\title{
O panóptico do desenvolvimento e o discurso ambiental institucional: uma reflexão a partir do Amazonas
}

\section{The panoptic of development and institutional environmental discourse: a reading from the state of Amazonas}

Francisca Dionéia Ferreira - Mestranda em Ciências Ambientais, pelo Programa de PósGraduação em Ciências Ambientais da Universidade Federal do Amazonas (UFAM). E-mail: dioneia_ferreira@hotmail.com

Francimara Souza da Costa - Doutora em Ciências Socioambientais, pela Universidade Federal do Pará (UFPA). Professora da Faculdade de Ciências Agrárias da Universidade Federal do Amazonas (UFAM). E-mail: francimaracosta@yahoo.com.br

\section{Resumo}

A Amazônia figura como o grande lócus da biodiversidade nos discursos ambientais em âmbito global, e o estado do Amazonas concentra boa parcela dessa biodiversidade em seu território. A relevância dessas riquezas naturais ganha destaque nos discursos, difundida como agenda prioritária nas ações baseadas na noção de sustentabilidade. Por meio de uma revisão bibliográfica, este artigo faz uma reflexão a respeito da constituição e dos efeitos do discurso ambiental institucional no Amazonas, apresentando uma relação deste com o panóptico do desenvolvimento sustentável. Observa-se que o discurso ambiental, enquanto exercício de poder, tem sido instrumento na construção de estratégias para a consolidação de instituições governamentais e não governamentais relacionadas à temática ambiental, ao mesmo tempo que tem sido observada pouca efetividade prática na melhoria das condições de vida das populações que habitam as áreas de floresta no estado, além de muitas vezes não haver real aderência a tal discurso no campo da ação e prática por parte das instituições que o propagam.

\section{Palavras-chave}

Discurso ambiental. Governança. Desenvolvimento sustentável. Amazônia.

\begin{abstract}
The Amazon is regarded as the major locus of biodiversity in environmental discourses globally, and the State of Amazonas concentrates a good portion of this biodiversity in its territory. The relevance of these natural riches is highlighted in discourses, disseminated as a priority agenda in actions based on the notion of sustainability. By means of a bibliographical review, this article presents a reflection on the constitution and the effects of the institutional environmental discourse in Amazonas, presenting a relationship between this and the panopticon of sustainable development. It is observed that the environmental discourse as an exercise of power has been an instrument in the construction of strategies for the consolidation of governmental and non-governmental institutions related to the environmental theme, at the same time that little practical effectiveness has been observed in improving the living conditions of populations that inhabit the forest areas in the State, in addition to the usual lack of true adherence to this discourse in the field of action and practice by the institutions that propagate it.
\end{abstract}

\section{Keywords}

Environmental discourse. Governance. Sustainable development. Amazonia. 


\section{INTRODUÇÃO}

Historicamente o discurso acompanha a evolução da sociedade, permeando seus processos e difundindo as ideias dos grupos dominantes. No âmbito dessa evolução, a Revolução Industrial é um importante marco para se considerar na análise do poder do discurso sobre a sociedade. O discurso desenvolvimentista advindo desse processo firmou novos padrões de produção de riquezas, consumo e lucro. Como consequência, o discurso do progresso impulsionou o deslocamento das populações do campo para a cidade, acentuando a pobreza e a degradação ambiental, uma vez que a industrialização aumentou a demanda e a pressão por recursos naturais, muitas vezes em detrimento da manutenção e conservação da biodiversidade (PEREIRA, 2017).

A constatação desses passivos da industrialização trouxe à tona os discursos ambientais, incentivando a reflexão em torno das relações entre os seres humanos e o seu ambiente natural. A reunião de intelectuais e interessados pelo tema em torno das preocupações ambientais impulsionou os debates mundiais, organizando-se de um lado o discurso da soberania, em que os países reclamavam seus direitos de explorar suas riquezas, e, do outro, a ideia da necessidade de imposição de medidas para frear o esgotamento dos recursos naturais (MARQUES FILHO, 2018).

Orlandi (2009) afirma que o discurso se constitui na medida em que o sujeito é atravessado pelas formações discursivas e ideológicas como um exercício de poder, devidamente interpelado pelos aparelhos ideológicos do Estado, e para a sua composição deve-se considerar as condições de produção do sujeito. Isso explica como o discurso desenvolvimentista ganhou força durante a Revolução Industrial, uma vez que o poder estava concentrado nas mãos dos proprietários dos fatores de produção das riquezas.

No estado do Amazonas, os discursos ambientais sofrem grande influência das características peculiares da região, relacionadas principalmente com a biodiversidade que está concentrada em seu território. Independente do setor ou agenda discutida, a condição desse estado como centro de concentração de biodiversidade emerge nos discursos, em alguns casos como vantagem comparativa em relação a outras regiões do país que não possuem riquezas naturais, e, em outros, como entrave ao desenvolvimento da região (SOUZA, 2019).

$\mathrm{Na}$ constituição do discurso como exercício de poder, o estado do Amazonas tem utilizado o componente ambiental, baseado na noção de sustentabilidade, como um contraponto à ideia de que a conservação da biodiversidade seja um entrave ao desenvolvimento da região. É importante 
ressaltar que a temática ambiental permeia tanto os discursos institucionais como os discursos do cidadão em geral, com a construção de um senso comum difusor da ideia do Amazonas como um lugar rico em biodiversidade e passível de exploração sustentável (SANTOS, 2010).

Nos discursos, o termo "sustentabilidade" vem sendo utilizado indistintamente pelas instituições vinculadas à temática ambiental, tais como Ministério do Meio Ambiente, Secretarias Estaduais de Meio Ambiente, Institutos Ambientais, Secretarias Municipais de Meio Ambiente e algumas organizações da sociedade civil, sem que sejam observadas na prática iniciativas da aplicabilidade dessa noção em escala. Tanto nos discursos governamentais como nos discursos das organizações da sociedade civil, a noção de sustentabilidade figura como algo presente e central na reprodução da sociedade no Amazonas (MARQUES FILHO, 2018).

O discurso da sustentabilidade tem sido a base para a articulação das políticas públicas no Amazonas. Entretanto, observa-se que a abrangência das iniciativas com esse viés ainda é de baixa escala, refletindo o sistema de governança predominante no estado. Apesar da existência de uma estrutura envolvendo diferentes instituições em múltiplas escalas de atuação, a baixa presença dos órgãos governamentais responsáveis pelas ações de comando e controle, sobretudo no interior do estado, tem comprometido o fortalecimento da governança, no sentido de que uma governança fortalecida se concretiza em um cenário em que cada ator institucional ocupa seu espaço de competência no território (COSTA; FERNANDES, 2016).

Este estudo se caracteriza como uma análise da relação entre o panóptico do desenvolvimento e o discurso ambiental no estado do Amazonas, apresentando elementos que demonstram o reflexo dessa relação sobre as populações locais. O trabalho apresenta elementos que podem embasar uma avaliação da real efetividade do uso do termo "sustentabilidade" presente nos discursos, considerando a necessidade de conservação da biodiversidade e a melhoria das condições de vida das populações amazônicas.

\section{METODOLOGIA}

O estudo foi elaborado a partir de uma revisão bibliográfica de caráter analítico a respeito da relação entre o panóptico do desenvolvimento e o discurso ambiental institucional no estado do Amazonas. A coleta de dados ocorreu por meio de consultas em artigos científicos, Dissertações de Mestrado e Teses de Doutorado em plataformas de bases de dados: SciELO, Google Acadêmico, 
Capes e Plataforma Sucupira. Para a realização das buscas nas plataformas, foram utilizados os termos-chave: "discurso ambiental", "Amazonas", "análise do discurso", "política ambiental no Amazonas" e variantes.

Após a seleção dos critérios de inclusão previamente definidos, foram seguidas estas etapas: leitura exploratória, leitura seletiva e leitura analítica, com a escolha do material que melhor se adequou aos objetivos do presente estudo, e para finalizar, a leitura interpretativa, seguida da redação e discussão do assunto objeto deste estudo, conforme detalhamento a seguir (MARCONI; LAKATOS, 2003):

- Definição do objeto: Identificação de estudos científicos publicados nas plataformas acessadas sobre os discursos ambientais que incidiram sobre o estado do Amazonas;

- Parâmetros de busca: Durante a busca foram usados como parâmetros "Discurso ambiental no Amazonas", "Discurso no Amazonas" e "Discurso sobre o Amazonas";

- Triagem para inclusão: Nesta etapa foram realizadas leituras para avaliação da pertinência dos documentos em relação ao objeto deste estudo;

- Extração de dados: Leitura dos documentos para identificação e extração das informações relevantes;

- Síntese dos dados: Análise e classificação das informações coletadas para categorização;

- Redação: Sistematização e consolidação dos resultados.

\section{O DISCURSO AMBIENTAL INSTITUCIONAL}

A partir dos anos 1970, o discurso da sustentabilidade ganhou força nos debates relacionados às questões ambientais e ao desenvolvimento social no mundo inteiro. Em pouco tempo, sustentabilidade tornou-se palavra de ordem, utilizada nos mais diferentes contextos e mais diversos grupos e extratos sociais (SILVA; BAUER; GUERRA, 2015). Entretanto, em sua maioria, os discursos relacionados a esse termo são superficiais, muitas vezes desconectados do contexto local de quem emite a opinião.

Compreendendo o discurso como a exposição de opiniões que expressam uma maneira de pensar e agir em relação a um certo assunto, com o intuito de influenciar o raciocínio e as percepções do ouvinte ou leitor (MARTINS, 2015), é importante atentar ao processo ideológico e histórico no qual o discurso se dá. Segundo Foucault, ideologia e história devem ser consideradas para a compreensão do discurso, pois este parte de um processo de significação que se 
modifica ao longo do tempo, influenciando as verdades construídas socialmente e sendo influenciado por estas (FOUCAULT, 1997).

Pêcheux (2008) diz que a análise do discurso deve ser permeada por uma visão holística, envolvendo os diversos campos do conhecimento, uma vez que o discurso nunca se apresenta completo ou concluído. $\mathrm{O}$ autor chama atenção para a necessidade de considerar as condições sociais e históricas do discurso, dirigindo-se a todos os espaços e momentos.

No campo ambiental, as verdades surgidas a partir do discurso foram influenciadas por determinadas relações de poder, impulsionadas muitas vezes pela imprensa, por meio de propagandas, ou até mesmo na divulgação científica, refletindo na constituição de um campo de saber-poder (SILVA; HENNING, 2019). Para Foucault (1997), o saber e o poder são construções sociais formadas a partir de relações; logo, é preciso considerar o saber que permeia o discurso ambiental, transmutado nas relações de poder que o rodeiam.

Em termos institucionais, o discurso ambiental foi impulsionado pela Organização das Nações Unidas no final dos anos 1980. A partir da exposição dos efeitos negativos do modelo vigente de produção e consumo, o desenvolvimento sustentável foi proposto como saída para frear a destruição dos recursos naturais, apontado como uma forma menos impactante de produzir, capaz de garantir o equilíbrio entre o acúmulo de riquezas e a manutenção dos recursos naturais. A sustentabilidade passou então a permear os discursos de empresas, consumidores, movimentos sociais, organizações governamentais e não governamentais.

No entanto, para Casara (2016), o discurso da sustentabilidade se tornou mais uma forma de poder do mercado. O saber ambiental, nesse processo, passou a ser construído em torno de uma "consciência verde", que na verdade nada mais é que um "desencargo de consciência". O ciclo de produção e consumo desenfreado não foi rompido, apenas modificado, pintando-se o "consumo verde" como estilo de vida harmônico entre consumo e natureza. Porém, o consumo sustentável, ecológico, verde ou responsável continuou sendo vendido como mercadoria.

No Brasil, a agenda ambiental evoluiu priorizando a construção de arranjos em torno de estratégias de conservação, por meio da criação e implementação de uma estrutura de Governo voltada para a temática ambiental, com a institucionalização gradativa dos diferentes órgãos da pasta ambiental. Inicialmente, foi criada uma Secretaria Especial do Meio Ambiente em 1973, com posterior aprimoramento dessa estrutura por meio da criação do Instituto Brasileiro do Meio Ambiente e dos Recursos Renováveis (Ibama) em 1989 e, posteriormente, a criação do Ministério do Meio Ambiente em 1993, seguida da 
criação da Agência Nacional de Águas (ANA) em 2001, e da criação do Instituto Chico Mendes de Conservação da Biodiversidade (ICMBio) em 2007 (SILVA; LIMA, 2013, p. 339).

A despeito do marco regulatório e dos sistemas de agências ambientais criados no âmbito governamental, no campo institucional a questão ambiental também é permeada pela concepção da natureza como um bem econômico. A legislação ambiental e seus instrumentos de controle mantêm, em certa medida, os interesses das empresas e consumidores, inserindo-se apenas formas de adequação do consumo à "produção sustentável". Assim, as empresas que outrora consideravam a questão ambiental como entrave ao desenvolvimento, passaram a demonstrar interesse na importância de minimizar impactos em seus processos, adotando uma postura empresarial de apoio à conservação ambiental, pelo menos no âmbito do discurso.

Wenceslau, Antezana e Calmom (2012) afirmam que o discurso ambiental institucional é baseado no discurso da resolução de problemas, que engloba os discursos da racionalidade administrativa, do pragmatismo democrático e do racionalismo econômico. A racionalidade administrativa parte do princípio de que os problemas ambientais podem ser resolvidos pela onipotência do Estado, a partir do conhecimento científico, técnico e da burocracia. O pragmatismo democrático incorpora a participação dos cidadãos nas decisões políticas relacionadas aos problemas ambientais, e o racionalismo econômico aposta na ação inteligente dos mecanismos de mercado para alcançar o interesse público. Esses discursos são derivados da "Tragédia dos Comuns" de Garrett Hardin (1968), em que se defende que a inserção dos recursos naturais no sistema de mercado atende aos interesses públicos, e por isso seria um mecanismo mais eficiente na restrição da utilização de determinados recursos.

Ao ganhar valor de mercado, a questão ambiental foi sendo legitimada pelos marcos regulatórios que figuram como mediadores da relação entre meio ambiente e empresas. Os estudos voltados para a comprovação da redução dos impactos negativos da produção em escala sobre os recursos naturais abriram espaço para o surgimento de iniciativas pela normatização das rotinas industriais, com certificações e auditorias, em um esforço de harmonização das relações empresariais com o ambiente (MARQUES FILHO, 2018).

Fonseca e Bursztyn (2009) afirmam que a racionalidade econômica presente nos comportamentos e discursos ambientais se beneficia do valor social simbólico ou material agregado ao discurso em favor da conservação ambiental. Os autores ressaltam que em muitos casos existe uma lacuna entre a retórica e a prática do discurso ambiental, o que muitas vezes se dá em função da ausência de 
ética na rotina das instituições que o professam ou que de alguma forma apoiam ações de conservação ambiental.

O advento da ISO 14000 e demais certificações ambientais, em que as empresas que demonstram apoio à conservação ambiental são mais valorizadas, representa o bem simbólico do discurso, vinculado aos valores sociais dominantes (BOURDIEU, 2005). O discurso ambiental emerge aqui como capital simbólico, transmutado posteriormente em capital cultural, capital econômico ou capital político. A institucionalização do discurso ambiental influenciou mudanças no modo de ver e professar a importância da conservação ambiental, de um momento em que o discurso de seus defensores era taxado de utópico para um momento em que a sociedade passou a reconhecer sua importância.

A agenda ambiental institucionalizada resultou então na propagação da ideologia de que é possível um progresso em bases sustentáveis, construindo o imaginário social da possibilidade da conservação dos recursos atrelada à economia de mercado (ASSIS; ZHOURI, 2011). As indústrias passaram, então, de "vilãs" a colaboradoras na manutenção dos recursos, fazendo-se crer que houve uma transição do seu comportamento predatório para um comportamento conservacionista.

O marketing institucional realizado em torno dos termos "sustentabilidade", "economia verde", "ecologicamente correto", entre outros, contribuiu sobremaneira para essa "virada de jogo". Como exemplo, podem ser citadas as propagandas geradas em torno da "grande" contribuição das empresas para a preservação do meio ambiente quando desligam seus equipamentos nos fins de semana, dos pequenos investimentos para o reaproveitamento de resíduos, das reciclagens ou das trocas de alguns insumos poluentes - ações que passaram a ser divulgadas como "banhos verdes" das indústrias, propagando o ideário de um processo de ambientalização dos empreendimentos que impactam a natureza (ALMEIDA, 2002).

Esses exemplos demonstram como o discurso materializa sua capacidade para estabelecer verdades universais em uma sociedade regida pela concorrência (FONSECA; BURSZTYN, 2009). Aqueles que ocupam posições dominantes determinam os modos de pensar, sentir e agir da sociedade consumidora, deixando para as políticas de Estado o importante papel na criação de instrumentos que salvaguardem a mínima estabilidade diante do poder do discurso, e cuidando de suas consequências diante da adesão de seguidores e da ampliação do seu campo de influência.

Nessa concepção, o discurso ambiental passou a tomar parte nas políticas públicas de desenvolvimento, ordenando as formas de interação e ação entre 
os componentes da arena ambiental (PORTO, 2015). A exemplo, a divulgação do controle ambiental pelo Ibama e órgãos ambientais estaduais sobre a relação entre a pecuária e o avanço do desmatamento tem influenciado a mudança de hábitos alimentares, impulsionando o aumento de adeptos da alimentação orgânica, vegetariana e vegana.

$\mathrm{Na}$ Amazônia, o fortalecimento institucional da agenda e do discurso ambiental tem situado a região no centro das discussões estratégicas, em função das suas características de megabiodiversidade, bem como da emergência do combate às frentes de devastação. Uma das estratégias utilizadas para o controle ambiental na região foi a criação de Unidades de Conservação (UC) (PEREIRA, 2017).

O intuito era salvaguardar os recursos naturais, no caso das UCs de proteção integral, e perpetuar o modo de vida tradicional das populações da área, nas UCs de uso sustentável. No entanto, alguns estudos apontam limitações na eficiência da criação das UCs no controle ambiental. Por exemplo, houve um avanço do desmatamento dentro de UCs da Amazônia nos últimos anos, aumentando de 6\% em 2008 para 12\% em 2015 (IMAZON, 2017).

As comunidades rurais da região amazônica possuem então um duplo desafio: o de habitar com baixo impacto no meio da floresta, ao mesmo tempo que precisam ser guardiãs de sua biodiversidade. Tomando como referência a relação harmônica de alguns grupos humanos em áreas de floresta (CIDREIRANETO; RODRIGUES, 2017), o discurso ambiental institucional passou a propagar a importância da preservação desse modo de vida para a manutenção da biodiversidade. A política de gestão ambiental introduziu medidas para ampliar a participação dos usuários de recursos naturais nas decisões ambientais, especialmente institucionalizando e incentivando práticas de manejo comunitário (ESPADA; SOBRINHO, 2015).

Por outro lado, mudanças no modo de vida dessas comunidades baseadas no aumento do uso de recursos oriundos do extrativismo vegetal e animal podem ser consideradas fatores de risco ao equilíbrio da biodiversidade local. Essas mudanças muitas vezes são promovidas pelos próprios órgãos ambientais, devido a suas fragilidades institucionais. $\mathrm{O}$ discurso da institucionalização que garante o ordenamento no uso dos recursos, resulta por vezes em novos conflitos, tendo pouca efetividade sobre a relação harmônica entre uso e conservação. Costa e Ravena (2017) afirmam que as regras institucionais impostas sobre o uso da terra, quando não são acompanhadas de uma presença efetiva do Estado, ampliam os conflitos, ao invés de solucioná-los.

Desse modo, verifica-se a premente necessidade de um alinhamento entre o discurso ambiental e a prática das instituições. A institucionalização da questão 
ambiental trouxe avanços reais, como a redução do desmatamento, o aumento de produtos relacionados à economia verde e uma maior internalização dos custos das externalidades ambientais (WENCESLAU; ANTEZANA; CALMON, 2012). Entretanto, é preciso cuidar para que não ocorra uma banalização da sustentabilidade também no campo institucional (FONSECA; BURSZTYN, 2009), envidando-se esforços para a construção de um sistema de governança que reduza a distância entre o discurso e a eficiência das práticas institucionais no trato das questões ambientais.

\section{O PANÓPTICO DO DESENVOLVIMENTO E O DISCURSO AMBIENTAL NO AMAZONAS}

O panóptico diz respeito à instauração de práticas de poder que visam disciplinar os indivíduos por meio das inter-relações entre conhecimento e controle. Por sua vez, o ambiente surge como o meio pelo qual o poder passa a regular a vida, mediante discursos que enfatizam os perigos e riscos da degradação da biodiversidade, ou, por outro lado, enfatizando modelos de desenvolvimento que façam frente a esses perigos (SANTOS, 2010).

O panóptico do desenvolvimento, permeado pela ideologia do desenvolvimento sustentável, tem sido o mecanismo presente nos discursos sobre o estado do Amazonas. Nos acordos para o financiamento de projetos estruturantes, predomina a ideia do imperativo da conservação, com a exigência de práticas e políticas que aliem a estratégia de crescimento econômico à inserção de ações voltadas para a proteção ou conservação da biodiversidade.

A estrutura do tipo panóptico de Foucault (1979) mostra como alguns agentes possuem o poder de monitorar e sancionar o comportamento dos demais sujeitos sem que eles possam discernir se estão ou não sendo monitorados. Essa estrutura pode ser observada nos discursos que defendem o desenvolvimento do estado do Amazonas, por considerarem as populações tradicionais pouco desenvolvidas, ignorando o seu modo de vida.

O discurso sobre a Amazônia, bem como sobre o Amazonas, se compôs a partir da visão dos governos nas diferentes esferas de poder, que viam essa região como um vazio demográfico e um local com grande potencial para exploração dos recursos naturais (SECRETO, 2007). O Governo Federal articulou diversos programas no sentido da promoção da ocupação na Amazônia, como uma fronteira a ser cruzada e uma barreira ao desenvolvimento a ser vencida.

Ainda segundo Secreto (2007), o Amazonas foi articulado nos discursos do governo como uma solução para a demanda nordestina por melhores condições 
de vida, em função da seca que assolava aquela região. Ao mesmo tempo, com o advento do período da borracha, houve uma necessidade de mão de obra para a exploração desse potencial na Amazônia, aliando-se o discurso do vazio demográfico à emergência do potencial econômico do Amazonas.

No discurso do Presidente Getúlio Vargas proferido em Manaus no ano de 1940, houve menção ao clima amazônico como um impedimento à atração de contingentes humanos de outras regiões para a ocupação da região, e ele também defendeu que somente o nordestino, com seu "espírito pioneiro", poderia se embrenhar na floresta, abrindo caminho para a exploração da seringueira silvestre (SECRETO, 2007).

Para Swain (2009), inicialmente a Floresta Amazônica foi estigmatizada como um "inferno verde" nos discursos governamentais dos anos 1970. O governo fazia uma alusão ao livro de Alberto Rangel (1908), apregoando que todas as características peculiares da região, como clima quente e úmido, presença de insetos e dificuldade de acesso na mata fechada, figuravam como entraves ao desenvolvimento e à extração dos recursos com o mínimo de conforto. Entretanto, posteriormente os governos mudaram suas visões e passaram a defender o estado do Amazonas como um lugar com grande potencial para o desenvolvimento de negócios, inclusive frisando a facilidade de acesso aos recursos naturais e à terra para a criação de gado.

Em 1966, o governo criou a Superintendência de Desenvolvimento da Amazônia (Sudam) como instituição promotora dessa agenda de ocupação da região, de modo que essa instituição, juntamente com o Banco da Amazônia (Basa), foi responsável pela difusão do discurso desenvolvimentista aliado ao ambientalismo para a região (ANTUNES; OLIVEIRA, 2017). O Governo Federal disponibilizava recursos financeiros para que as empresas pudessem explorar o potencial dos recursos naturais no estado, e os discursos que aliavam desenvolvimento à exploração dos recursos naturais eram evidenciados na atuação da Sudam e do Basa, que fomentavam as obras de infraestrutura e a implantação de indústrias.

A Zona Franca de Manaus foi criada no ano de 1967 também no bojo desse processo, como uma estratégia para o desenvolvimento nodal da região, com as empresas do distrito industrial gerando o surgimento de toda uma cadeia de empreendimentos, sustentada pelas demandas da população local.

Esse discurso da emergência de ocupação econômica do Amazonas foi largamente difundido por meio das instituições governamentais, inclusive com o reforço de argumentação baseado na renúncia fiscal e incentivos fiscais para as empresas interessadas em atuar na Zona Franca de Manaus. 
As dimensões continentais do Amazonas, pouco povoado, emergiam nas articulações políticas como estratégias para a atração de investimentos e, ao mesmo tempo, serviam à necessidade de premente ocupação da região para fazer frente às ameaças de invasão do território nacional pelos países vizinhos. O slogan "Integrar para não entregar", do governo do Presidente Castelo Branco, ilustra como os discursos foram carregados dessa agenda emergencial de ocupação do Amazonas (SOUZA, 2019).

Nesse momento, o discurso das organizações da sociedade civil, ou organizações não governamentais (ONGs), como eram conhecidas, ganhou força, com posicionamento a favor da ideia da necessidade de preservação da biodiversidade e promoção da justiça social no estado, para garantir a manutenção do modo de vida das populações locais. A Cúpula da Terra de 1992 considerava o modo de vida das populações tradicionais, incluindo populações indígenas, seringueiros e ribeirinhos, a melhor alternativa sustentável em face do modelo predatório do desenvolvimento (ZHOURI, 2006).

Para Zhouri (2019), na Amazônia, as tensões envolvendo “árvore” e "gente" foram fortemente mediadas pelas ONGs que atuam na região. Os discursos das ONGs ambientalistas abordavam de forma subliminar como a noção de desenvolvimento estava mudando a relação dos povos com a floresta, transformando-a de uma relação harmônica para uma relação de oposição. Essa afirmação pode ser ilustrada por meio da peça publicitária da ONG World Wild Fund For Nature (WWF), publicada no jornal inglês Financial Times, em 31 de dezembro de 1994, que tinha como objetivo a arrecadação de recursos, e que continha uma fotografia de um índio cortando uma árvore, com os dizeres: "Ele está destruindo sua própria floresta. Para detê-lo, você enviaria a cavalaria ou um antropólogo?”.

Os discursos das ONGs, assim como suas estratégias para a Amazônia e para o Amazonas, foram ancorados na ideia do manejo florestal comunitário e na noção de desenvolvimento sustentável, situando essas visões em posições de poder no campo ambiental. A visão e o discurso de que o conhecimento técnico se faz necessário para a sustentabilidade da Amazônia atribui um recorte florestal às questões ambientais, destacando a dimensão global do desenvolvimento sustentável como uma resposta para a conservação e o desenvolvimento da região (MARQUES FILHO, 2018).

Entretanto, é importante ressaltar que, muitas vezes, tanto os discursos governamentais quanto os discursos das ONGs consideram os recursos florestais da região como ativos, de caráter difuso ou público, desconsiderando seu uso ancestral pelas populações tradicionais. Predomina a visão mercadológica da 
floresta como fonte de mercadorias para a manutenção do hegemônico modelo de acumulação (ZHOURI, 2006).

Essa visão mercadológica da floresta se utiliza do panóptico para corroborar o discurso da necessidade de investir em grandes empreendimentos que utilizem os recursos naturais da região, como condição para a garantia do desenvolvimento. O discurso utilizado é baseado no pragmatismo democrático, explicado acima, levando as populações locais a crer que estão seguras ao participar das decisões sobre a implementação dos empreendimentos. Entretanto, muitas vezes, as propostas já chegam prontas às consultas públicas, e a população é levada apenas à sua legitimação. A maioria das obras de infraestrutura implementadas na região não incluem as populações locais no seu processo de concepção e nem sequer há consulta sobre a necessidade do empreendimento ou sobre o interesse neste (BRUM, 2019).

O caso do processo de reconstrução da rodovia BR-319 no Amazonas ilustra essa questão. As populações tradicionais não foram consultadas acerca de sua construção no período de 1970 a 1977, e no atual processo de reconstrução iniciado em 2014, estão sendo "ouvidas" apenas por força do licenciamento. Suas vozes estão constantemente sofrendo pressões políticas e econômicas para que o empreendimento seja executado (BRUM, 2019).

Segundo Queiroz (2016), de um modo geral, os discursos ambientais institucionais predominantes no Amazonas estão alinhados aos interesses de corporações econômicas internacionais, sendo que a geração de renda das atividades florestais, com a contratação de mão de obra local, por exemplo, figura aliada ao discurso da inclusão social e da conservação ambiental apenas como forma de legitimar suas ações.

O panóptico do desenvolvimento sustentável surge nos discursos como algo facilmente aceitável, e assimilável pela sociedade, exercendo um papel fundante nas questões ambientais, como se sua simples evocação fosse o suficiente, tal qual uma "palavra mágica" com poder para solucionar todos os problemas ambientais (QUEIROZ, 2016). Entretanto, apesar do transcurso de muitos anos desde o surgimento desse termo, ele ainda constitui uma noção abstrata, sem que tenha sido implementado na prática em escala, o que torna vazios os discursos que o contêm.

A partir disso, é possível então considerar que a institucionalização da noção do desenvolvimento sustentável não promoveu grandes rupturas com os modelos anteriores de desenvolvimento, baseados estritamente no aspecto econômico. Faz-se necessária a busca de novas formas de conceber o 
desenvolvimento, nas quais os princípios da sustentabilidade possam de fato se sobrepor à ideia da exploração econômica dos recursos, de forma a atender as necessidades reais da sociedade (e não as necessidades criadas pelo sistema econômico), sem comprometer a manutenção dos recursos naturais das regiões que os contêm.

\section{CONCLUSÃO}

Os discursos ambientais institucionais no Amazonas ao longo do tempo foram permeados pelos contextos históricos e políticos brasileiros ou internacionais, muitas vezes refletindo muito mais as tendências globais do que as temáticas e problemas locais. É importante ressaltar que por um longo período, a Amazônia e o Amazonas estiveram no centro da temática ambiental, mas a argumentação não emergia do campo local, do centro da floresta, mas fora incorporada a partir da visão de atores institucionais externos.

Como argumentação, a noção de desenvolvimento sustentável se aliou ao modo de vida das populações tradicionais, mas de forma a legitimar os discursos institucionais, sem aderência na prática local. A sustentabilidade econômica e ambiental não dialoga com o campo social, pois no estado do Amazonas há ocorrência de populações pobres em locais com muitos recursos naturais e grande potencial ambiental e econômico.

Ao longo do tempo, observou-se que os argumentos da sustentabilidade ou do manejo florestal comunitário não alcançaram o rompimento da barreira do discurso, para de fato refletir sobre o desenvolvimento sustentável do estado. O que se vê, mesmo em locais que possuem o controle institucional dos recursos naturais, como unidades de conservação e assentamentos rurais, é a permanência da degradação ambiental e da pobreza, percebendo-se pouca efetividade prática do discurso da sustentabilidade, baseado na melhoria dos aspectos econômicos, sociais e ambientais.

O caminho para que haja efetividade nos discursos ambientais passa pelo fortalecimento da governança como mecanismo de condução ao alcance da equidade, princípio fundamental de garantia da justiça social e da participação das populações locais nos espaços de poder decisório. É preciso alinhar o discurso ambientalista à prática institucional, incentivando-se cada ator institucional a ocupar seu espaço de competência de forma efetiva e transformadora. 


\section{REFERÊNCIAS}

ALMEIDA, F. O bom negócio da sustentabilidade. Rio de Janeiro: Nova Fronteira, 2002. 101 p.

ANTUNES, P. T. S.; OLIVEIRA, G. C. A. Discurso do Banco da Amazônia: mudança de posição ideológica e seus reflexos na publicidade. The ESPecialist: Descrição, Ensino e Aprendizagem, São Paulo, v. 38, n. 2, p. 1- 23, 2017.

ASSIS, W. F. T.; ZHOURI, A. Representar territórios e desfigurar conflitos ambientais: o discurso do desenvolvimento sustentável na publicidade Brasileira. Novos Cadernos NAEA, Belém, v. 14, n. 2, p. 117-140, 2011. BOURDIEU, P. O poder simbólico. Rio de Janeiro: Bertrand Brasil, 2005. 322 p. BRUM, E. Brasil, construtor de ruínas: um olhar sobre o país, de Lula a Bolsonaro. Porto Alegre: Arquipélago Editorial, 2019. 304 p.

CASARA, M. O discurso do desenvolvimento sustentável, marketing e simulacro. Revista Vida Pastoral, São Paulo, ano 57, n. 307, jan./ fev. 2016. Disponível em: https://www.vidapastoral.com.br/artigos/temas-sociais/odiscurso-do-desenvolvimento-sustentavel-marketing-e-simulacro/. Acesso em: 15 mar. 2020.

CIDREIRA-NETO, I. R. G.; RODRIGUES, G. G. Relação homem-natureza e os limites para o desenvolvimento sustentável. Revista Movimentos Sociais e Dinâmicas Espaciais, Recife, v. 6, n. 2, p. 142-156, 2017.

COSTA, F. A.; FERNANDES, D. A. Dinâmica agrária, instituições e governança territorial para o desenvolvimento sustentável da Amazônia. Revista de Economia Contemporânea, Rio de Janeiro, v. 20, n. 3, p. 517-552, 2016.

COSTA, F. S.; RAVENA, N. Territórios e cercas simbólicas em regimes de propriedades comuns na Amazônia. Geosul, Florianópolis, v. 32, n. 63, p 159-178, 2017.

ESPADA, L. V.; SOBRINHO, M. V. Manejo comunitário e governança ambiental para o desenvolvimento local: análise de uma experiência de uso sustentável de floresta na Amazônia. Administração Pública e Gestão Social, Viçosa, v. 7, n. 4, p. 169-177, 2015.

FONSECA, I. F.; BURSZTYN, M. A banalização da sustentabilidade: reflexões sobre governança ambiental em escala local. Sociedade e Estado, Brasília, DF, v. 24, n. 1, p. 17-46, 2009. 
FOUCAULT, M. Microfísica do poder. Tradução Roberto Machado. Rio de Janeiro: Edições Graal, 1979. 296 p.

FOUCAULT, M. Arqueologia do saber. Rio de Janeiro: Forense, 1997. 244 p.

HARDIN, G. The tragedy of the commons. Science, Washington DC, v. 162, n. 3859, p. 1243-1248, 1968.

IMAZON. Unidades de conservação mais desmatadas da Amazônia Legal (2012-2015). IMAZON, Belém, 2017. Livros e livretos. Disponível em: https://imazon.org.br/unidades-de-conservacao-mais-desmatadas-daamazonia-legal-2012-2015/. Acesso em: 20 mar. 2020.

MARCONI, M. A.; LAKATOS, E. M. Metodologia científica. 5. ed. São Paulo: Atlas, 2003. 310 p.

MARQUES FILHO, L. C. Capitalismo e colapso ambiental. 3. ed. Campinas: Editora da Unicamp, 2018. 736 p.

MARTINS, R. S. Ambientalismo e sustentabilidade: um olhar sobre o discurso ambiental. NORUS, Rio de Janeiro, v. 3, n. 4, p. 138-154, 2015.

ORLANDI, E. P. Análise de discurso: princípios e procedimentos. 8. ed. Campinas: Pontes, 2009. 100 p.

PÊCHEUX, M. O discurso: estrutura ou acontecimento. Tradução Eni P. Orlando. Campinas: Pontes, 2008. 35 p.

PEREIRA, C. F. Estado e agronegócio: etnografia de um processo de regularização fundiária e descaracterização de territórios no Sul do Amazonas. 2017. 294 f. Tese (Doutorado em Antropologia Social) - Programa de Pós-Graduação em Antropologia Social, Universidade Federal do Amazonas, Manaus, 2017.

PORTO, J. R. S. Conexões, apropriações e exclusões no discurso do desenvolvimento territorial no Brasil. Novos Cadernos NAEA, Belém, v. 18, n. 1, p. 145-168, 2015.

QUEIROZ, S. P. L. Políticas públicas para o turismo sustentável no Estado do Amazonas: perspectivas e desafios, 2013 - 2016. 2016. 151 f. Dissertação (Mestrado em Ciências do Ambiente e Sustentabilidade na Amazônia) Programa de Pós-Graduação em Ciências do Ambiente e Sustentabilidade na Amazônia, Universidade Federal do Amazonas, Manaus, 2016.

RANGEL, A. Inferno verde: cenas e cenários do Amazonas. Lisboa: Ed. Typ. Minerva, 1908. 128 p. 
SANTOS, L. F. S. O panóptico verde: notas sobre os regimes de ambientalidade. Somanlu, Manaus, v. 10, n. 1, p. 304-475, 2010.

SECRETO, M. V. A ocupação dos “espaços vazios” no governo Vargas: do "Discurso do rio Amazonas" à saga dos soldados da borracha. Estudos Históricos, Rio de Janeiro, v. 10, n. 40, p. 115-135, 2007.

SILVA, D. F.; LIMA, C. G. F. C. Empresas e meio ambiente: contribuições da legislação ambiental. Revista Interdisciplinar INTERthesis, Florianópolis, v. 10, n. 2, p. 334-359, 2013.

SILVA, L. S.; HENNING, P. C. Problematizando o campo de saber da educação ambiental. Pro-Posições, Campinas, v. 30, e20170124, p. 1-24, 2019. SILVA, M. P.; BAUER, V.; GUERRA, A. F. S.

AmbientalMENTEsustentable, Florianópolis, v. 2, n. 20, p. 1035-1059, 2015. SOUZA, M. História da Amazônia: do período pré-colombiano aos desafios do século XXI. Rio de Janeiro: Record, 2019. 392 p.

SWAIN, T. N. Amazonas Brasileiras? Os discursos do possível e do impossível. Intervenções Feministas, [S. l.], 31 mar. 2009. Disponível em: http:// intervencoesfeministas.mpbnet.com.br/textos/tania-amazonasbahia.pdf. Acesso em: 05 mar. 2020.

WENCESLAU, J.; ANTEZANA, N. L.; CALMON, P. D. P. Políticas da terra: existe um novo discurso ambiental pós Rio +20? Cadernos EBAPE. BR, Rio de Janeiro, v. 10, n. 3, p. 584-604, 2012.

ZHOURI, A. O ativismo transnacional pela Amazônia: entre a ecologia política e o ambientalismo de resultados. Horizontes Antropológicos, Porto Alegre, ano 12, n. 25, p. 139-169, 2006.

ZHOURI, A. Mineração, violência e resistências: um campo aberto à produção de conhecimento no Brasil. CROLAR, Boltzmannstr, Berlin, v. 8, n. 1, p. 69$71,2019$. 